\title{
OPEN X-ray micro-computed tomography reveals a unique morphology in a new click-beetle (Coleoptera, Elateridae) from the Eocene Baltic amber
}

\begin{abstract}
Robin Kundrata $^{1 凶}$, Andris Bukejs ${ }^{2}$, Alexander S. Prosvirov ${ }^{3}$ \& Johana Hoffmannova ${ }^{1}$
Beetle fossils are a rich source of information about the palaeodiversity and evolutionary history of the order Coleoptera. Despite the increasing rate of fossil research on click-beetles (Coleoptera: Elateridae), the most diverse group in the superfamily Elateroidea, their fossil record has remained largely unstudied. This may be caused by the combination of their rather uniform external morphology and the suboptimal state of preservation and visibility in most fossil specimens. Here, we used X-ray micro-computed tomography to reconstruct the morphology of an interesting click-beetle from Eocene Baltic amber, which had some principal diagnostic characters obscured by opaque bubbles and body position. Our results suggest that the newly described Baltelater bipectinatus gen. et sp. nov. belongs to tribe Protelaterini within subfamily Lissominae. Since Protelaterini have a predominantly Gondwanan distribution, our discovery is of a great importance for the historical biogeography of the group. Very distinctive are the bipectinate antennae with 11 antennomeres and with rami beginning on antennomere IV, which are not found in any recent Elateridae. The discovery of a new clickbeetle lineage from European Eocene amber sheds further light on the palaeodiversity and historical diversification of the family as well as on the composition of the extinct amber forest ecosystem.
\end{abstract}

Over recent decades, there has been an increasing amount of research attention directed towards insect fossils. This led to the discoveries of various previously unknown lineages, and helped to improve our knowledge on the origin, evolution, palaeodiversity and palaeobiogeography of insect groups at all taxonomic levels ${ }^{1-5}$. Among fossils, amber inclusions play an important role because they represent the finest and most complete insect fossil remains due to their three-dimensional nature, and are relatively easily compared with extant forms ${ }^{6-13}$. However, amber fossils are often in a bad state of preservation that does not enable the visualization of crucial morphological features ${ }^{14,15}$. In order to overcome this problem, micro-computed tomography can be employed. This non-destructive technology allows the effective reconstruction of fossilized structures in three dimensions using digital software even for suboptimally preserved specimens ${ }^{16}$. Recently, micro-CT data were used in palaeontological studies focused on the morphology of various fossil animal taxa, including, for example, arachnids ${ }^{17,18}$, myriapods ${ }^{19}$, crustaceans $^{20}$, insects ${ }^{3,21}$, and also vertebrates ${ }^{22,23}$. This method is used not only for habitus observation but often also for reconstruction of internal organs including genitalia, as documented by a number of recent papers dealing especially with Baltic amber Coleoptera ${ }^{24-27}$.

Baltic amber constitutes the largest known Paleogene source of fossilized plant resin worldwide, and contains the most diverse assemblage of fossil insects to date ${ }^{2,28,29}$. Although the inclusions in Baltic amber are well-known for their preservation in exquisite detail, and the number of publications on these fossils has been rapidly growing, there have been uncertainties regarding the geographic origin, botanical provenance, and age of this amber. Baltic amber is not found in its original stratigraphic position; instead, it has been redeposited mainly in marine sediments and fluvial deposits. It occurs in the "Blue Earth" layers of the Baltic region, especially in the Samland Peninsula within the Kaliningrad Oblast (Russia), but also in other countries along the coast of the Baltic Sea,

${ }^{1}$ Department of Zoology, Faculty of Science, Palacky University, 17. listopadu 50, 77146 Olomouc, Czech Republic. ${ }^{2}$ Institute of Life Sciences and Technologies, Daugavpils University, Vienības 13, Daugavpils 5401, Latvia. ${ }^{3}$ Department of Entomology, Faculty of Biology, Moscow State University, Leninskie gory 1/12, Moscow, Russia 119234. ${ }^{\square}$ email: robin.kundrata@upol.cz 
including Denmark, Germany, Poland, Sweden, and the Baltic states ${ }^{29}$. The original habitat of the amber forest has been assumed to be a thermophilic, humid mixed forest ${ }^{30}$ in a warm temperate, humid, equable climate without thermal seasonality ${ }^{11}$. There has been conflicting evidence about the source plant of this amber, and this was officialy termed the "Tertiary Baltic amber mystery"131. For many years it was believed that Pinus succinifera (Göppert) Conwentz was the main resin producer ${ }^{6,32}$; however, more recent research brought more candidates, including the representatives of Sciadopityaceae, Araucariaceae, Pinaceae, and Cupressaceae ${ }^{8,33-35}$. The age of Baltic amber has also been the subject of much debate, usually due to the repeated re-deposition of the amber, the broad range of the ancient resin-producing forest, and its probable long-term existence ${ }^{36}$. Using various methods such as $\mathrm{K}-\mathrm{Ar}$ dating, palynological biostratigraphic analysis or comparison of the faunas from different amber sources, most estimates generally range from the middle to upper Eocene (Lutetian to Priabonian, 47.8-37.8 Ma) $)^{28,36-40}$.

Elateridae, or click-beetles, is the largest family in the polyphagan superfamily Elateroidea. Its typical representatives are well-known for their hard, compact body and the pro-mesothoracic clicking mechanism ${ }^{41,42}$; however, there are several soft-bodied lineages currently included in the family which were historically considered separate families ${ }^{43-45}$. The composition, phylogeny and natural classification of Elateridae are far from fully understood, despite the effort of numerous recent studies ${ }^{43,44,46,47}$. Elateridae comprise more than 10,000 extant species worldwide ${ }^{42}$, and the fossil record includes approximately 300 species, although the placement of many of them needs thorough investigation ${ }^{48,49}$. They originated and greatly diversified during the Mesozoic ${ }^{2,50,51}$, and are among the most common beetle families recorded in Baltic amber ${ }^{28,52}$. Until now, 16 click-beetle species have been described from Baltic amber, with one classified in Agrypninae, one in Cardiophorinae, two in Den-

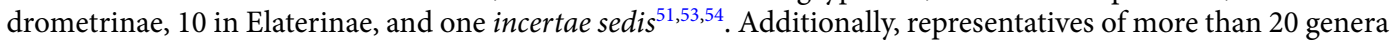
have been reported from Baltic amber without detailed descriptions ${ }^{28,52,55-59}$, and many yet unstudied specimens are waiting to be examined in various collections.

In this study, we use X-ray micro-computed tomography $(\mu \mathrm{CT})$ to reconstruct the morphology of a Balticamber click-beetle specimen which has some principal diagnostic characters obscured by opaque bubbles and suboptimal body position (Fig. 1). Results of our investigation suggest that the studied specimen represents a new genus and species in the tribe Protelaterini within the subfamily Lissominae. The discovery of the first lissomine click-beetle from European Eocene amber sheds further light on the palaeodiversity and historical diversification of the family as well as on the composition of the extinct amber forest ecosystem.

\section{Results}

Based on its divergent morphology (Figs. 1-5, Supplementary Videos 1-3), we describe here Baltelater bipectinatus gen. et sp. nov., which we classify in the tribe Protelaterini within the click-beetle subfamily Lissominae.

Systematic paleontology. Family Elateridae Leach, 1815

Subfamily Lissominae Laporte, 1835

Tribe Protelaterini Schwarz, 1902

= Senodoniini Schenkling, 1927

= Sphaenelaterini Stibick, 1979

Type genus. Protelater Sharp, 1877.

Diagnosis. Body elongate, oblong, rather convex; scape more or less straight and moderately long; prothorax and elytra not tightly joined together, narrowed at junction of prothorax and elytra; prosternal chin-piece short and usually truncate; hypomeron without cavities for reception of antennae; pro- and mesotrochanters less than 2.5 times as long as wide; tibia subcylindrical and not compressed laterally; tarsomeres I-IV each with membranous lamella apico-ventrally (these lamellae less developed especially on tarsomeres I and II); styli of ovipositor present, small, attached subapically or medially.

Composition and distribution. 47 described species classified in nine recent genera, i.e., Anaspasis Candèze, 1882 (4 spp., South America), Austrelater Calder \& Lawrence, 1993 (3 spp., Australia), Protelater Sharp, 1877 (12 spp., New Zealand), Rostricephalus Fleutiaux, 1918 (1 sp., East and South East Asia), Senodonia Laporte, 1838 (20 spp., South, East and South East Asia), Sossor Candèze, 1883 (1 sp., South East Asia), Sphaenelater Schwarz, 1902 (3 spp., New Zealand), Tunon Arias-Bohart, 2013 (1 sp., South America), Valdivelater Lawrence \& Arias, 2009 (2 spp., South America) ${ }^{47,60,61}$, and one monotypic fossil genus, i.e., Baltelater gen. nov. (North European Baltic amber).

Baltelater gen. nov. urn:lsid:zoobank.org:act:A0AD4F5E-2B55-4731-8B40-F4A0470DA29A.

Type species. Baltelater bipectinatus sp. nov.; by present designation.

Diagnosis. Adult male. Head globular, deflexed; eye large, prominent, entirely visible, mouthparts hypognathous; mandible rather broad and short, bidentate; frons slightly overhanging base of labrum; antennal insertions moderately widely separated, supra-antennal carinae short, frontal carina medially obsolete; antenna inserted in small crescent-shaped socket flush with head capsule, with 11 antennomeres, bipectinate from antennomere IV; pronotum relatively short compared to elytra, wider than long, widest at posterior angles, posterior angles short, slightly divergent, non-carinate; lateral carina complete, strongly sinuate near posterior angle in lateral view; pronotosternal sutures very shortly excavate anteriorly, distinctly curved inwards; prosternum anteriorly truncate, without chin-piece; prosternal process rather long, slightly roundly emarginate behind procoxae, without subapical tooth; procoxal cavities moderately widely separated; protrochantin not visible; pro- and mesotrochanters elongate, slightly more than twice as long as wide; mesocoxal cavities narrowly separated, open to both mesanepisternum and mesepimeron; mesocoxae large, conical; metaventrite distinctly elongate; metacoxal plate rather narrow, gradually narrowed towards elytron; tarsomeres I-III apicoventrally with short membranous 


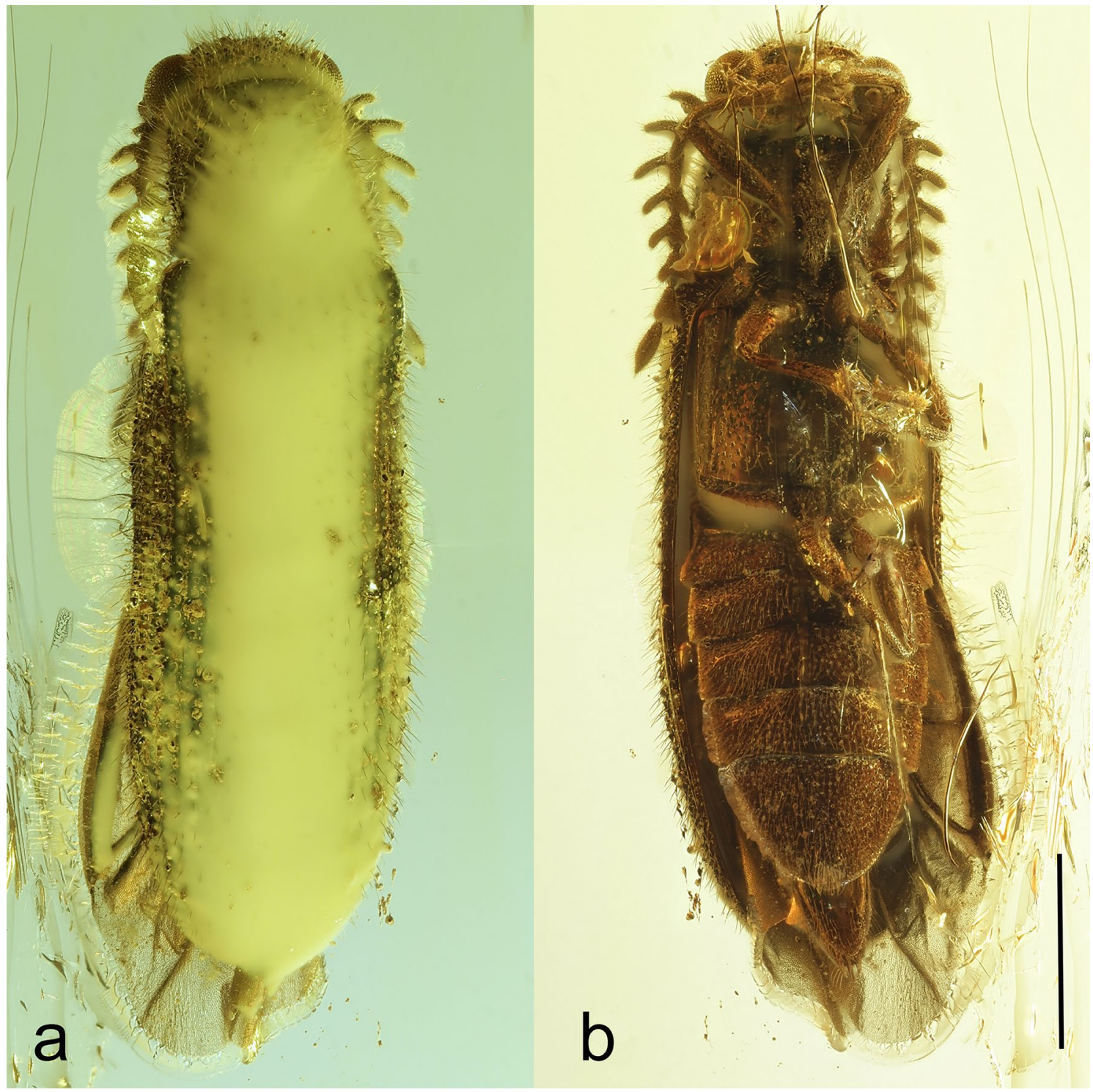

Figure 1. Habitus of Baltelater bipectinatus gen. et sp. nov., holotype: (a) dorsal view; (b) ventral view. Scale bar $=1.0 \mathrm{~mm}$. Credit: Jonas Damzen (Vilnius, Lithuania).

lamellae and IV with longer lamella; pretarsal claw simple; aedeagus with median lobe slightly surpassing tip of parameres, and with parameres having short and sharp subapical hook. For more details, see the description of B. bipectinatus sp. nov. below, Figs. 1-5, and Supplementary Videos 1-3.

Etymology. Derived from the words "Baltic" (referring to Baltic amber) and "Elater" (a genus name in Elateridae). Gender: masculine.

Composition and distribution. Only B. bipectinatus sp. nov. (Eocene Baltic amber).

Baltelater bipectinatus sp. nov. (Figs. 1-5, Supplementary Videos 1-3).

urn:lsid:zoobank.org:act:5CCA61A9-9FE4-4922-A39C-A6467CE16099.

Type material. Holotype, adult male, "6685" (MAIG) (ex coll. Jonas Damzen, JDC 8374). A complete beetle is included in an elongate, transparent, yellow amber piece with dimensions of $48 \times 19 \times 3 \mathrm{~mm}$, and preserved without supplementary fixation. Syninclusions consist of two different specimens of Nematocera (Diptera), many stellate Fagaceae trichomes, and several small gas vesicles.

Type stratum and age. Baltic amber from Eocene "Blue Earth" layers, predominantly Bartonian age (41.2-37.8 Ma) (for more details, see Material and methods).

Type locality. Baltic Sea coast, Yantarny settlement (formerly Palmnicken), Sambian (Samland) Peninsula, Kaliningrad Oblast, Russia.

Diagnosis. As for the genus.

Description. Body (Figs. 1, 2, Supplementary Video 1) $5.4 \mathrm{~mm}$ long, $1.6 \mathrm{~mm}$ wide, elongate, slightly convex, uniformly brown, covered with rather dense, semi-erect pubescence. 


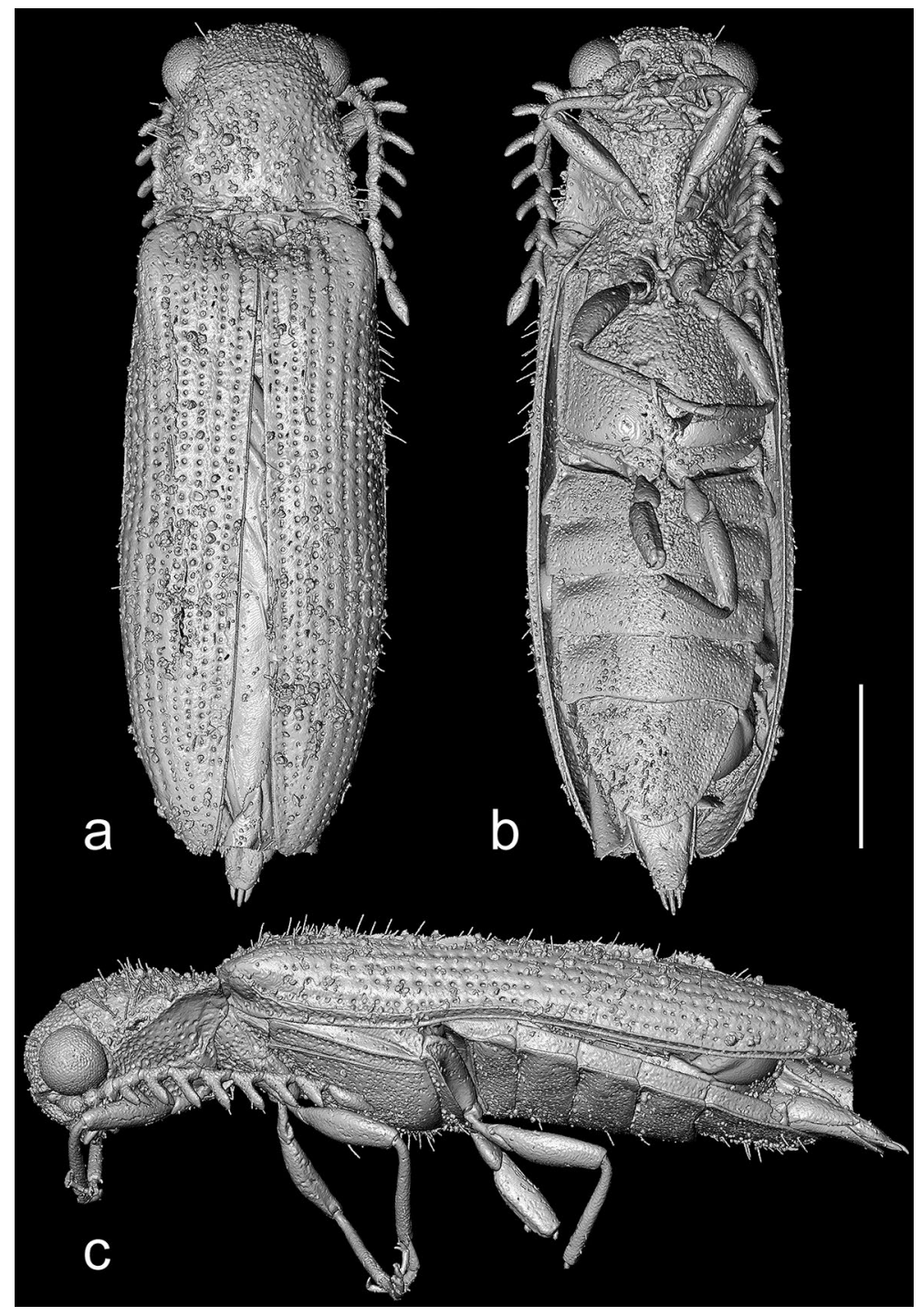

Figure 2. X-ray micro-CT renderings of Baltelater bipectinatus gen. et sp. nov., holotype, habitus: (a) dorsal view; (b) ventral view; (c) left lateral view. Scale bar $=1.0 \mathrm{~mm}$.

Head (Figs. 1-3) globular, deflexed, only partly retracted to prothorax so that eyes are entirely visible, including eyes distinctly wider than anterior margin of pronotum but slightly narrower than pronotum posteriorly; surface rather densely punctate; punctures large, coarse, deep, rounded to suboval, intervals between punctures usually less than a puncture diameter; densely covered with long, semi-erect pubescence. Frons apically slightly overhanging base of labrum; antennal insertions moderately widely separated, surface above them distinctly raised, forming short supra-antennal carinae, frontal carina not developed medially; frontoclypeal region slightly inflexed, transverse, about twice as wide as long (Fig. 3a-c). Eyes large, protuberant, entirely visible from above. Labrum rather small, transverse, convex, coarsely punctate, apically rounded. Mandible robust, rather broad and short, bidentate, lateral edge distinctly curved, region between apical teeth very short. Maxilla with palpus four-segmented, moderately long; palpomere I short, transverse; palpomere II elongate, about 1.7 times as long as wide; palpomere III slightly shorter than palpomere II; apical palpomere about as long as combined length of palpomeres II-III, about 1.7 times as long as wide at widest place, hatchet-like. Labium with palpus threesegmented, short; apical palpomere slightly longer than wide, hatchet-like. Antenna (Figs. 1-4, Supplementary Video 2) inserted in small crescent-shaped socket flush with head capsule, with 11 antennomeres, bipectinate from antennomere IV, stout, moderately long, slightly surpassing elytral humerus. Scape long, robust, notably thicker than remaining antennomeres; antennomeres II-III subequal in length, simple, approximately 1.4 times as long as wide, gradually widened apically; length ratio of antennomeres II-XI equal to $1.0: 1.0: 1.3: 1.4: 1.4$ : $1.5: 1.6: 1.7: 1.7: 2.5$; antennomeres IV-X slightly progressively increasing in length towards apex, bipectinate, with rami arising subbasally, slightly flattened to subcircular in cross-section, slightly longer than respective antennomere stems in antennomeres IV-VII, approximately as long as stem in antennomere VIII, and slightly shorter than respective stems in antennomeres IX-X (ramus/antennomere stem length ratio equals to $1.2: 1.3$ 


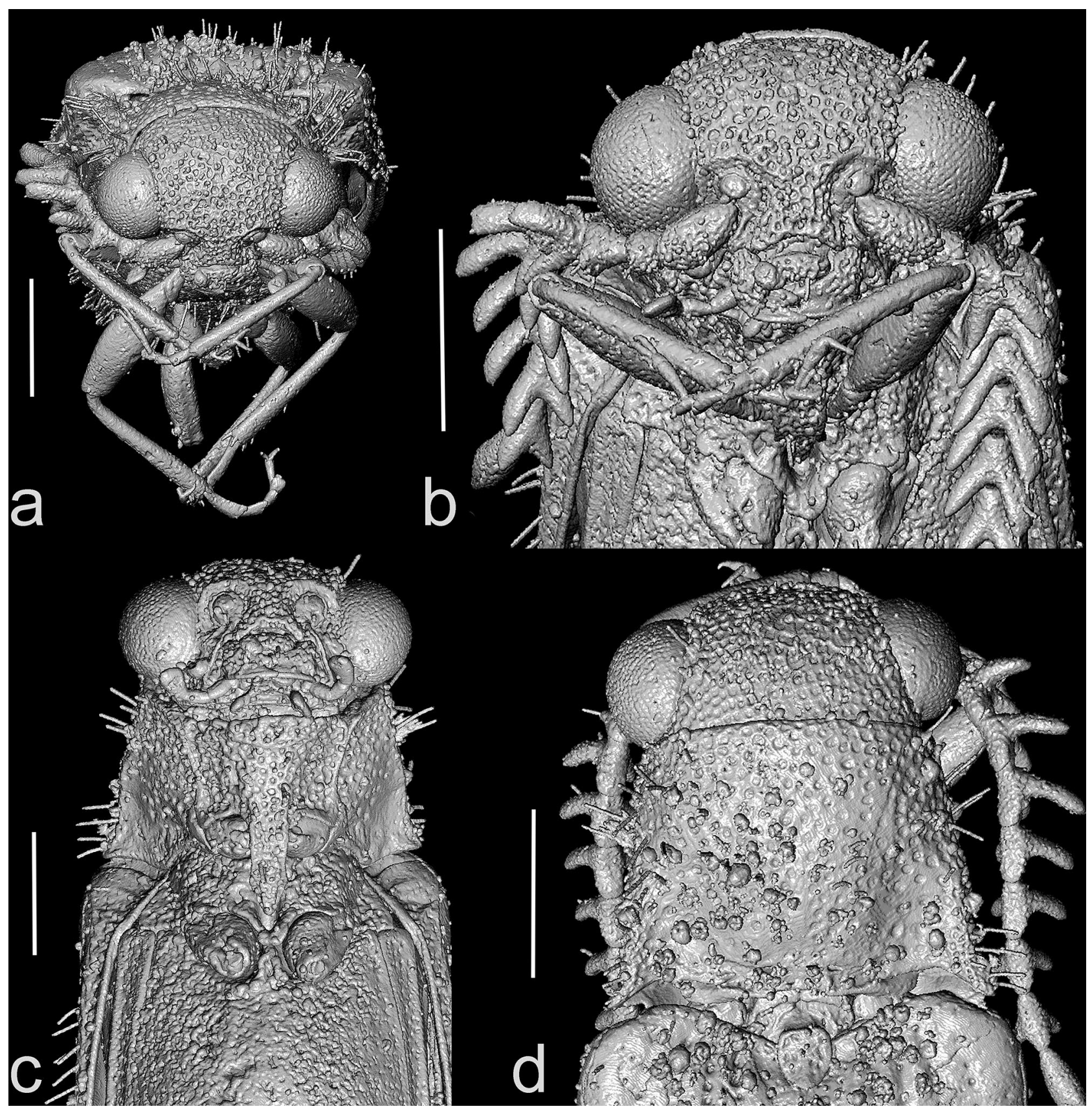

Figure 3. X-ray micro-CT renderings of Baltelater bipectinatus gen. et sp. nov., holotype: (a) head, frontal view; (b) head, frontoventral view; (c) head and thorax (legs removed), ventral view; (d) head and thorax, dorsal view. Scale bars $=0.5 \mathrm{~mm}$.

$: 1.3: 1.2: 1.0: 0.9: 0.8$ ); ultimate antennomere elongate, approximately three times as long as wide medially, widest at about middle, obliquely, distinctly narrowed apically, with apex narrowly rounded; all antennomeres moderately densely covered with semi-erect pubescence.

Pronotum (Figs. 2a, 3d) transverse, subtrapezoidal, widest at posterior angles, 1.1 times as wide as long anteriorly, 1.4 times as wide as long posteriorly, slightly convex, approximately 0.25 times as long as elytra. Anterior margin almost straight; anterior angles inconspicuous; lateral sides from dorsal view almost straight; posterior angles relatively short, sharp, slightly divergent, without apparent sublateral carina, apically narrowly rounded; posterior margin medially with shallow arcuate indentation, which is about as long as width of scutellar shield. Lateral carina distinct, complete, strongly sinuate near posterior angle in lateral view, in dorsal view visible only in posterior part, then hidden. Disc relatively sparsely punctate; punctures large, rounded, mostly separated by 0.5-2.0 times diameter of puncture, denser anteriorly, denser and smaller near posterior angles; surface densely covered with long, semi-erect pubescence. Hypomeron moderately densely covered with large, distinct punctures in anterior half and near pronotosternal sutures, almost smooth posteriorly near pronotal angles. Pronotosternal sutures very shortly excavate anteriorly, distinctly curved inwards. Prosternum (Figs. 1b, 2b, 3c) rather short, 


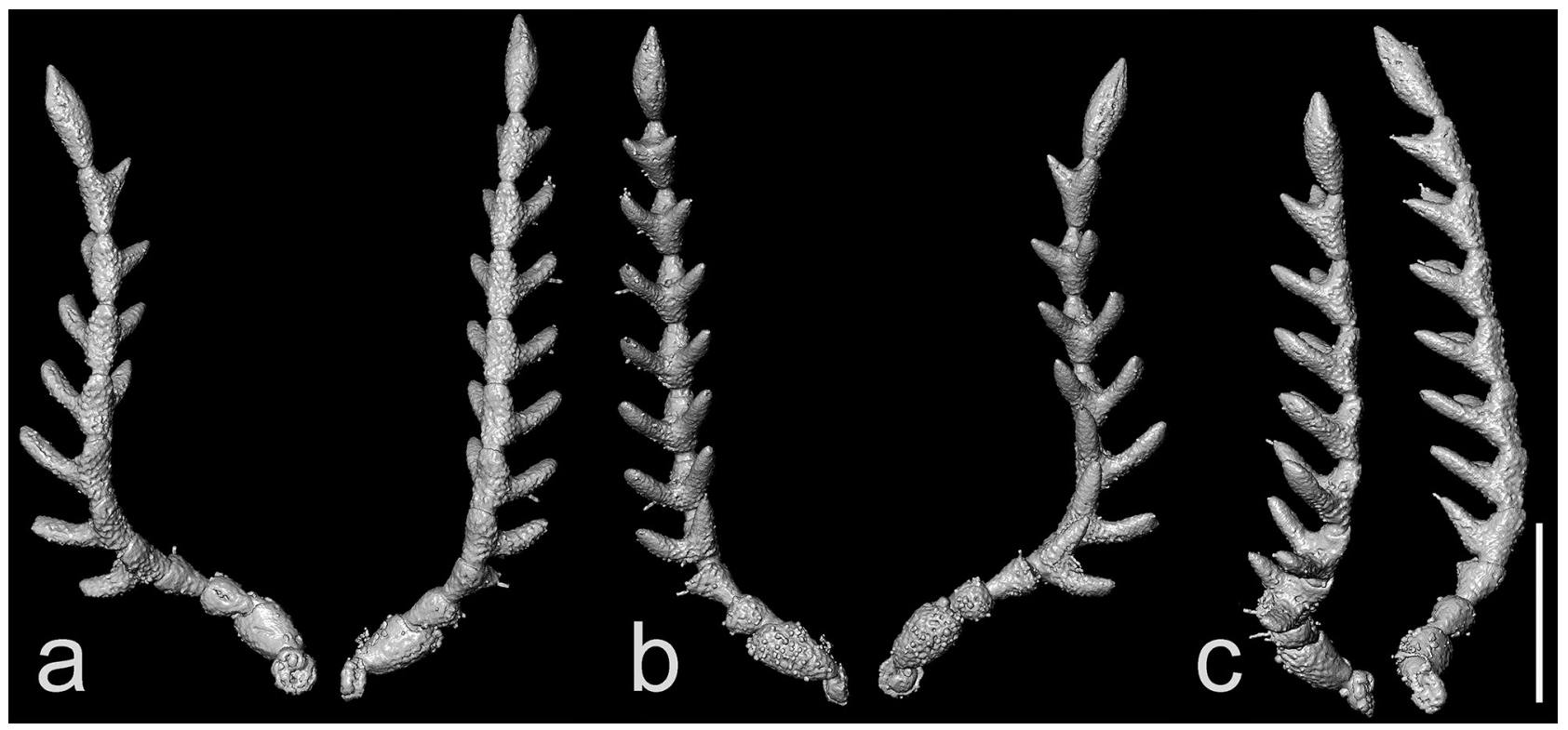

Figure 4. X-ray micro-CT renderings of Baltelater bipectinatus gen. et sp. nov., holotype, antennae: (a) dorsal view; (b) ventral view; (c) lateral view. Scale bar $=0.5 \mathrm{~mm}$.

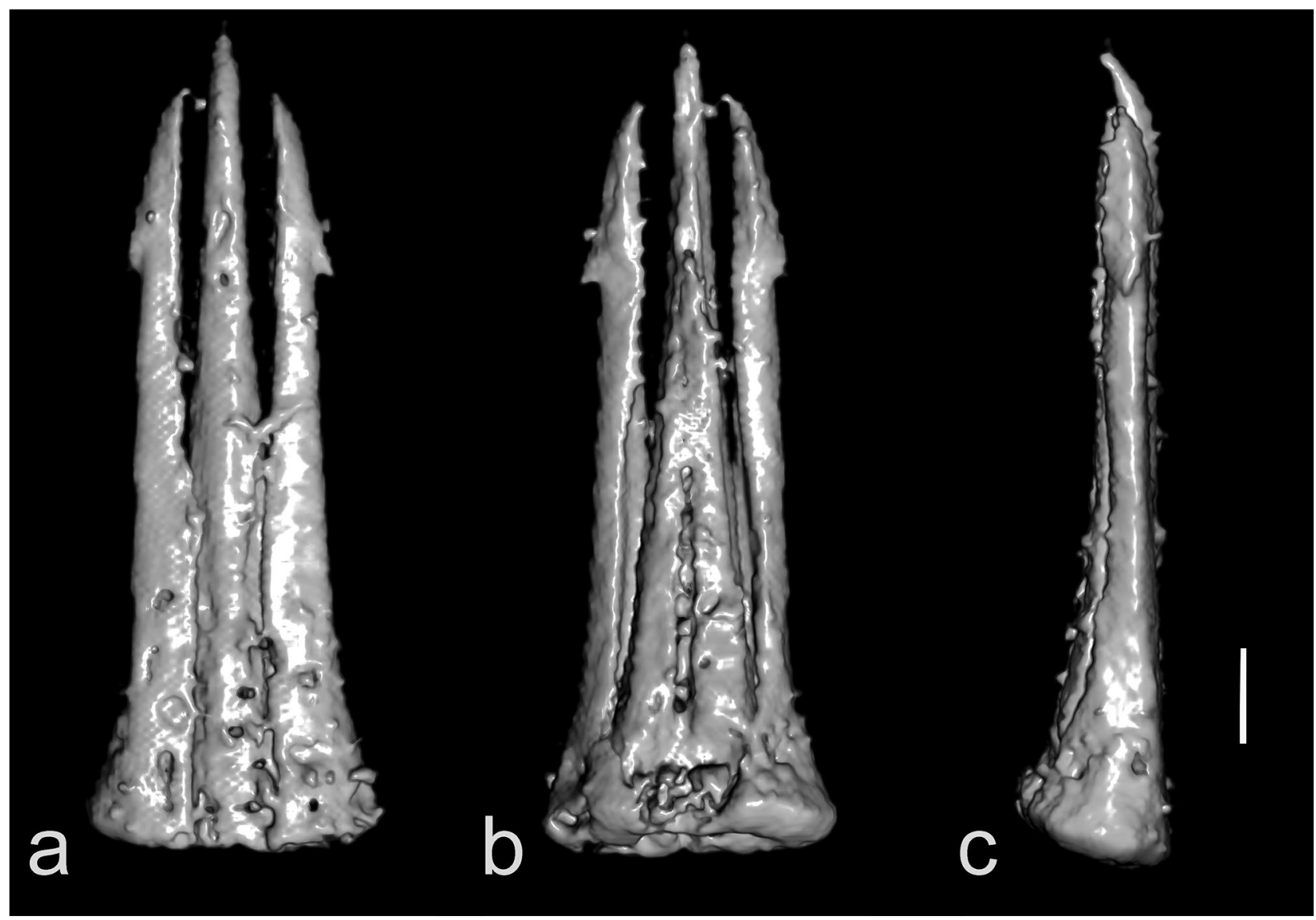

Figure 5. X-ray micro-CT renderings of Baltelater bipectinatus gen. et sp. nov., holotype, aedeagus (without phallobase): (a) dorsal view; (b) ventral view; (c) lateral view. Scale bar $=0.1 \mathrm{~mm}$. 
including prosternal process approximately 1.2 times as long as wide, in front of coxal cavities (i.e., excluding prosternal process) 0.6 times as long as wide, anteriorly truncate, without chin-piece. Prosternal process relatively long, slightly longer than prosternum in front of procoxal cavities, with sides subparallel-sided, slightly roundly emarginate behind procoxae, then abruptly narrowed towards apex, without apparent subapical tooth; surface uneven, coarsely punctate; apex narrowly rounded. Procoxal cavities subcircular, moderately widely separated; protrochantin not visible. Scutellar shield (Figs. 2a, 3d) about as long as wide, anterior margin almost straight; lateral sides and posterior margin rounded; surface covered with small punctures. Mesocoxal cavities narrowly separated, open to both mesanepisternum and mesepimeron; mesocoxae large, conical. Mesoventrite (Figs. 2b, 3c) transverse, slightly widened posteriorly; sides slightly sinuate; mesoventral process short, apically widely rounded; mesoventral cavity relatively shallow and with indistinct borders anteriorly, widened and with more distinct borders posteriorly. Metaventrite elongate, rather convex, moderately densely punctate; punctures smaller than those on prothorax; metanepisternum wider anteriorly and gradually narrowed towards posterior part. Metacoxal plate (Figs. 1b, 2b) rather narrow, abruptly emarginate near inner margin, only slightly, gradually narrowed towards elytron. Elytra (Fig. 2a,c) elongate, together approximately 2.5 times as long as wide, widest around apical 2/3; each elytron with striae formed by lines of large rounded punctures, which are separated by about diameter of a puncture; interstriae formed by smooth, convex ridges; pubescence dense, long, semi-erect to erect; elytral apices independently rounded. Hind wing well-developed, elongate. Leg slender, moderately long; pro- and mesotrochanters elongate, slightly more than twice as long wide; tarsomere I longest, about as long as tarsomeres II and III combined, tarsomere II longer than tarsomere III, tarsomere III longer than tarsomere IV, tarsomeres I-III ventrally with short lamellae, which are shortest on I, relatively short on II and slightly longer on III, tarsomere IV shortest, apicoventrally with well pronounced lamella, apical tarsomere elongate, slender; pubescence relatively sparse, semi-erect; pretarsal claw simple, moderately curved.

Abdomen (Figs. 1b, 2b,c) with five ventrites, first four of which seem to be more or less connate, with ventrite 5 free, lying on a different plane than ventrites $1-4$; length ratio of ventrites $1-5$ equal to $1.0: 1.2: 1.3: 1.5: 2.6$; ventrite 1 with intercoxal process short, subtriangular; posterolateral corners of ventrite 1 produced and roundly acute, those of ventrites 2-4 less produced and more rectangular; surface of all ventrites covered with moderately large punctures and semi-erect pubescence, both denser at margins. Abdominal sternite IX only partly visible, elongate, gradually narrowed towards apex, apically narrowly rounded, apico-laterally finely punctate and with semi-erect pubescence. Aedeagus (Fig. 5, Supplementary Video 3) elongate, about 2.8 times as long as wide. Median lobe elongate, slightly surpassing tip of parameres, basally thicker, gradually narrowed towards apex, apically narrowly rounded and slightly curved from lateral view. Paramere elongate, with short and sharp subapical hook at about $1 / 4$ paramere length when measured from apex; parameral apex with several long erect setae on outer margin. Phallobase not visible in the specimen.

Female and immature stages unknown.

Etymology. The specific name "bipectinatus" refers to the shape of the antennae (Fig. 4).

Biology. All known lissomine larvae are associated with rotten, decaying wood ${ }^{41}$, and therefore, we hypothesize that the larva of $B$. bipectinatus gen. et sp. nov. formed a part in the extinct amber forest ecosystem.

\section{Discussion}

The finding of a new click-beetle genus in Baltic amber highlights the importance of X-ray micro-computed tomography for reconstruction of morphology in fossil organisms, especially in cases when opaque bubbles and the position or contraction of appendages obscures crucial diagnostic characters (Fig. 1). Further, this discovery confirms Baltic amber as an invaluable substance for understanding terrestrial palaeodiversity and evolution of various organisms as well as for reconstructing extinct Paleogene ecosystems. The fossils entombed in the relatively young Eocene European ambers are almost always classified within present-day suprageneric taxa (with some rare exceptions ${ }^{21,62-65}$ ), and approximately half of them also in extant genera ${ }^{28}$. Since newly described supraspecific taxa in Baltic amber are relatively less common than those in older ambers (e.g., Burmese, Lebanese), they represent very important evidence of rich Eocene palaeodiversity.

Regarding the Elateridae, exceptionally preserved fossils from Eocene ambers provide significant information about the evolution and diversification of this beetle family ${ }^{2,6,28,53}$. During the mid-Paleogene, all major presentday subfamilies already existed and had diversified ${ }^{51}$, which is documented by the fossil record of Agrypninae, Elaterinae, Dendrometrinae, Cardiophorinae, Negastriinae, Pityobiinae, and Omalisinae (Table 1), and further supported by recent dated molecular phylogenies, which date back the origin of the main Elateridae lineages to the Mesozoic ${ }^{66-68}$. However, although Elateridae are quite common in various Mesozoic and Cenozoic amber deposits $^{1,2,28,69}$, their true diversity remains underexplored. This is mainly a result of their extremely homogeneous external appearance which is constrained by the development of the pro-mesothoracic clicking mechanism ${ }^{41}$. The problems surrounding a uniform morphology and multiple independent origins of various characters historically used for the delimitation of suprageneric taxa have greatly affected the classification of the group, which has been in a constant state of flux for both extinct and extant lineages ${ }^{41-43,51,70}$. This also affects the dating of the oldest known fossils for the subfamilies and hence for the whole family, since the placement of some earliest representatives of e.g., Protagrypninae (e.g., Elaterophanes Handlirsch, 1906), Dendrometrinae (Alaodima Dolin, 1980) and Cardiophorinae (Mionelater Becker, 1963) has recently been questioned ${ }^{51}$, and needs critical evaluation (Table 1). Most click-beetle higher taxa are not delimited by unique synapomorphies but rather by combinations of characters. These taxonomic definitions are often challenged by new discoveries and are limited to certain geographic regions ${ }^{41-43}$. Phylogenetic analyses based chiefly on morphology have shown that their results must be treated with caution ${ }^{70}$. Recent molecular analyses at least partly improved our understanding the phylogeny and classification of the present-day higher taxa ${ }^{43,44,46,47}$; however, this is not possible for fossils, for which we have only morphological data available. Therefore, for a systematic classification of the newly 


\begin{tabular}{|c|c|c|c|}
\hline Subfamily & Genus/species & Period/epoch, location & Age $(\mathrm{Ma})$ \\
\hline Agrypninae & $\begin{array}{l}\text { Species of genera Ageratus Dolin, 1980, Compsoderus Dolin, 1980, Litholacon Dolin, 1980, Cryptocardius } \\
\text { Dolin, } 1980\end{array}$ & Jurassic of Kazakhstan & $166.1-157.3$ \\
\hline Campyloxeninae & No fossils available & & \\
\hline Cardiophorinae & Mionelater planatus Becker, 1963 & Miocene of Mexico & $23.0-16.0$ \\
\hline Dendrometrinae & Alaodima grandis Dolin, 1980 & Jurassic of Kazakhstan & $166.1-157.3$ \\
\hline Elaterinae & Numerous undescribed genera and species & Cretaceous Burmese amber & $99.6-93.5$ \\
\hline Eudicronychinae & No fossils available & & \\
\hline Hemiopinae & No fossils available & & \\
\hline Lissominae & Baltelater bipectinatus gen. et sp. nov & Eocene Baltic amber & $38.0-33.9$ \\
\hline Morostominae & No fossils available & & \\
\hline Negastriinae & Species of genera Ganestrius Dolin, 1976 and Protoquasimus Dolin, 1976 & Jurassic of Kazakhstan & $166.1-157.3$ \\
\hline Oestodinae & No fossils available & & \\
\hline Omalisinae & Jantarokrama utilis Kirejtshuk \& Kovalev, 2015 & Eocene Baltic amber & $38.0-33.9$ \\
\hline Parablacinae & No fossils available & & \\
\hline Physodactylinae & No fossils available & & \\
\hline Pityobiinae & Cretopityobius pankowskiorum Otto, 2019 & Cretaceous Burmese amber & $99.6-93.5$ \\
\hline Protagrypninae & Two species of genus Elaterophanes Handlirsch, 1906 & Triassic of the United Kingdom & $208.5-201.3$ \\
\hline Subprotelaterinae & No fossils available & & \\
\hline Tetralobinae & No fossils available & & \\
\hline Thylacosterninae & No fossils available & & \\
\hline
\end{tabular}

Table 1. Overview of the Elateridae subfamilies with information on their earliest known fossils. For more details and references, see Kundrata et al. ${ }^{48}$.

discovered Baltelater gen. nov., we have to rely completely on our knowledge of adult morphology of all extinct and present-day lineages. However, this is even more difficult when some taxa are defined by characters on the hind wing venation or other difficult-to-observe characters ${ }^{43,70}$.

Baltelater gen. nov. clearly belongs to Elateridae due to its exposed labrum, projecting posterior angles of pronotum, concealed protrochantins, well-developed metacoxal plates, and presumably connate first four ventrites ${ }^{41,42}$. Within Elateridae, many subfamilies can be easily ruled out as the close relatives of Baltelater gen. nov. by their rather divergent morphology ${ }^{41-45,70,71}$ (see Supplementary Text 1 for more detailed information). Instead, Baltelater gen. nov. clearly belongs to the subfamily Lissominae due to the anteriorly convex head, the medially incomplete frontal carina, the bidentate mandibles with a mandibular apex broad when viewed anteriorly (perpendicular to plane of movement), the antennal rami beginning on antennomere IV, the posterior margin of pronotum simple, without sublateral incisions, the metacoxal plates rather narrow, the tarsomeres I-IV each with a membranous lamella apico-ventrally, and the tarsal claws without basal setae on outer flat portion ${ }^{41,47,61,71,72}$. Lissominae are currently divided into two tribes-Lissomini, which are widely distributed, mainly in the tropics and subtropics, and Protelaterini, which occur in the south temperate regions (Australia, New Zealand, South America) and Asia from the Himalayas and China to the Greater Sunda Islands ${ }^{43,47,61}$. Lissomini have a typically compact habitus with the prothorax and elytra tightly joined together and not narrowed at the junction of prothorax and elytra. Further, they have characteristic deep antennal cavities lying beneath the hypomera, notably long and curved scape, well-developed and rounded chin-piece, very long trochanters, tibia which is slightly widened towards apex and weakly compressed laterally, tarsomeres I-IV each with a long membranous lamella (those on II-IV usually longer than the base of respective tarsomere), and styli of ovipositor absent ${ }^{47,61}$. Protelaterini are morphologically more diverse than Lissomini, and they differ from the latter in having the prothorax and elytra not tightly joined together and narrowed at the junction of prothorax and elytra, the scape more or less straight and only moderately long, the hypomeron without cavities for reception of antennae, the prosternal chin-piece usually short and truncate, the pro- and mesotrochanters less than twice as long as wide, the tibia subcylindrical and not compressed laterally, the membranous lamellae on tarsomeres less developed, and styli of ovipositor present, small, attached subapically or medially ${ }^{47,61}$ (for details on morphology of both Lissominae tribes, see Figs. 2-7 in a recent open access study ${ }^{47}$ ). The monophyly and internal relationships of Protelaterini are disputable ${ }^{47,61,72}$. Recent molecular phylogenetic analysis ${ }^{47}$ recovered Austrelater Calder \& Lawrence, which is the most morphologically divergent genus within the Gondwanan Protelaterini, in a clade with Senodonia Laporte, 1838 and Sossor Candèze, 1883, which were traditionally placed near Dimini, far from the Lissominae. Unfortunately, the genera from South America and New Zealand were unavailable for the molecular analysis, mainly Protelater Sharp, 1877, which is the type genus of Protelaterini, and Sphaenelater Schwarz, 1902, which is the type genus of Sphaenelaterini, which is currently a synonym of Protelaterini ${ }^{47,61}$. Therefore, the classification of this group remains open to further study. Baltelater gen. nov. does not have the diagnostic characters of Lissomini but shares many morphological features with Protelaterini, e.g., the elongate body, the scape more or less straight and only moderately long, the prosternal chin-piece reduced, the hypomeron without deep antennal cavities, and the tibia subcylindrical and not compressed laterally. However, it differs from the extant Protelaterini genera in having the head exposed and not submerged in prothorax, and including eyes distinctly wider than the anterior margin of pronotum, the antenna bipectinate, the pro- and mesotrochanters 
slightly more than twice as long as wide (but still much shorter than in Lissomini), and abdominal ventrites 1-4 obviously not so tightly connected, with posterolateral corners more or less produced (Figs. 1-4, Supplementary Videos 1-3). The most morphologically similar extant genus is Austrelater from Australia, which, besides the typical Protelaterini characters, shares with Baltelater gen. nov. the large and strongly protuberant eyes, the similar shape of prothorax (including pronotum, prosternum, and pronotosternal sutures), metacoxal plates, and tarsomeres ${ }^{41,47,72}$ (Figs. 1-3; Fig. 6. in Kundrata et al. ${ }^{47}$ ). Due to the unresolved internal relationships within Protelaterini ${ }^{47}$, the exact position of Baltelater gen. nov. remains to be determined until the study combining molecular markers and morphology is carried out using the broader sampling including the genera from New Zealand and South America.

The discovery of the first representative of Protelaterini in the European Eocene amber shed important light on the biogeography of the group. Protelaterini were traditionally considered as an exclusively southern hemisphere lineage known only from Australia, New Zealand, and the southern Neotropics ${ }^{60,61}$. Recently, Kundrata et al. ${ }^{47}$ added Senodonia, Sossor and Rostricephalus, which expanded the distribution of this tribe into the Oriental and East Palearctic zoogeographical regions. Based on such distribution, Protelaterini may have been hypothesized as of a Gondwanan origin with a later expansion of their range to the eastern parts of Asia. However, our finding of Baltelater gen. nov. in the North European amber challenges this hypothesis. Similar cases in which the extant southern hemisphere taxon has its closest relatives in the Baltic amber include for example cyclaxyrid $^{9}$ and some trogossitid beetles ${ }^{73}$, and Mantophasmatodea ${ }^{74}$.

The genus Baltelater gen. nov. proposed here is very distinctive due to its bipectinate antennae (Figs. 1-4). Bipectinate or biflabellate antennae are generally rare among Coleoptera but they occur in several lineages of Elateroidea, including Brachypsectridae, Eucnemidae, Lampyridae, Phengodidae, Rhagophthalmidae, and Elateridae $^{75}$. Among Elateridae, these antennae can be found in several distantly related groups, and are composed of either 12 or, rarely, 11 antennomeres. Antennae with 12 antennomeres and with rami beginning on antennomere III were described in Alaolacon Candèze, 1865, Euphemus Laporte, 1838 (both Agrypninae: Hemirhipini), Lacon bipectinatus Riese, 1989 (Agrypninae: Agrypnini or Laconini), Oplanischius Chassain, 2010 (Elaterinae: Dicrepidiini) and Didymolophus Fairmaire, 1904 (Elaterinae: Aplastini or Morostominae), and those with 12 antennomeres and rami beginning on antennomere IV are known only in Pityobius LeConte, 1853 (Pityobiinae) and two species of Anisomerus Schwarz, 1897 (Eudicronychinae). Bipectinate antennae with 11 antennomeres and with rami beginning on antennomere III are known in Mocquerysia Fleutiaux, 1899 (Agrypninae: Hemirhipini) and Sinoaplastinus Schimmel, Platia et Tarnawski, 2008 (currently in Elaterinae: Aplastini but its position is dubious $)^{76}$. All above-mentioned taxa are extant. The genus Baltelater gen. nov., however, has antennae with 11 antennomeres and with rami beginning on antennomere IV; this condition is known only in one other fossil genus, Cretopityobius Otto, 2019 (Pityobiinae) from Cretaceous Burmese amber ${ }^{77}$. This means that these two fossil genera bear a type of antenna which is not seen in any of the recent Elateridae. Additionally, bipectinate antennae are reported for the first time in a representative of Lissominae.

The peculiar morphology of the newly discovered elaterid genus Baltelater gen. nov. from Eocene Baltic amber significantly contributes to a better understanding of the palaeodiversity and evolution of the group. Although the systematics of Elateridae is far from fully understood and a reliable phylogenetic position of many lineages cannot be resolved by the use of only morphological characters due to abundant homoplasies, it is obvious that the study of fossils from various geological epochs may play an important role in the recognition of still-undescribed diversity and descriptions of new evolutionary lineages.

\section{Material and methods}

This study is based on a specimen entombed in amber. The amber piece was polished by hand, allowing improved views of the included specimen, and it was not subjected to any supplemental fixation. Observations of this specimen were made using a Nikon SMZ 745 T stereomicroscope. The photographs were taken using a Canon 70D camera with a macro lens (Canon MPE- $65 \mathrm{~mm}$ ). Extended depth of field at high magnifications was achieved by combining multiple images from a range of focal planes using Helicon Focus v. 6.0.18 software. The X-ray micro-CT observations were conducted at Daugavpils University, Daugavpils, Latvia (DU) using a Zeiss Xradia 510 Versa system. Scans were performed with a polychromatic X-ray beam at an energy of $40 \mathrm{kV}$ and power of $3 \mathrm{~W}$. Sample to detector distance was set to $22.5 \mathrm{~mm}$, and a source to sample distance of $24.2 \mathrm{~mm}$ was used. Tomographic slices were generated from 2401 rotational steps through 360 -degrees of rotation, using a $4 \times$ objective, and the exposure time during each projection was set to $6 \mathrm{~s}$. Scanning parameters were set identical between two consecutive scans of the specimen in order to achieve smaller voxel resolution. Image stitching was carried out using automated reconstruction tool in Scout-and-Scan Control System (v14.0.14829.38124). Acquired images were binned $(2 \times 2 \times 2)$ giving voxel size of $3.49 \mu \mathrm{m}$. Images were imported into Dragonfly Pro (ver. 4.1$)$ software platform for interactive segmentation and 3D visualization. Volume renderings of X-ray microtomography of habitus, antennae and aedeagus are available in Supplementary Videos 1-3, respectively.

Body width of the examined specimen was measured at the widest part of the body, pronotal length at midline, and pronotal width at the widest part. Morphological terminology follows partly Calder ${ }^{41}$, Costa et al. ${ }^{42}$ and Kundrata et al. ${ }^{47}$, and the classification of Elateridae follows Kundrata et al. ${ }^{43}$. Although there are several hypotheses concerning the age of Baltic amber ${ }^{36,37,39}$, we follow the Middle Eocene (mostly Bartonian, 41.2-37.8 Ma) which was recently proposed for the extinct Central European resin-producing forests according to the stratigraphy of the Sambian amber deposits ${ }^{40}$. The material examined is deposited in the Museum of Amber Inclusions, University of Gdańsk, Poland (MAIG). For the morphological comparison of a new taxon with other Elateridae, we examined the representatives of all present-day suprageneric taxa deposited in various European and American museum and private collections, and additionally, we examined hundreds of fossil Elateridae from Baltic and Burmese amber deposited in the collections of the Paleontological Institute, Russian Academy of Sciences in 
Moscow, Russia (PIN), and collections of Robin Kundrata, Václav Dušánek (both Czech Republic), Andris Bukejs (Latvia), and Christel and Hans Werner Hoffeins (Germany). This included a majority of described species from ambers. For the remaining described fossil species, we used information from extensive literature, including the original descriptions (see Kundrata et al. $^{51}$, and references therein). The ZooBank LSID number for this publication is: urn:lsid:zoobank.org:pub:B56223D7-57A5-4543-863D-5CF845DAED3A.

\section{Data accessibility}

All data needed to evaluate the conclusions in the paper are present in the paper and/or the Supplementary Materials. The original micro-CT scans and the videos of 3D volume renderings are deposited in Zenodo (original scans: https://doi.org/10.5281/zenodo.4061092; Supplementary Video 1: https://doi.org/10.5281/zenod o.4049708; Supplementary Video 2: https://doi.org/10.5281/zenodo.4054747; Supplementary Video 3: https:// doi.org/10.5281/zenodo.4054755).

Received: 31 August 2020; Accepted: 4 November 2020

Published online: 19 November 2020

\section{References}

1. Rasnitsyn, A. P. \& Quicke, D. L. J. History of Insects (Kluwer Academic Publishers, Dordrecht, 2002).

2. Grimaldi, D. \& Engel, M. Evolution of the Insects (Cambridge University Press, New York, 2005).

3. Bai, M. et al. †Alienoptera - a new insect order in the roach-mantodean twilight zone. Gondwana Res. 39, 317-326 (2016).

4. Mey, W., Wichard, W., Müller, P. \& Wang, B. The blueprint of the Amphiesmenoptera - Tarachoptera, a new order of insects from Burmese amber (Insecta, Amphiesmenoptera). Foss. Rec. 20, 129-145 (2017).

5. Yamamoto, S. Fossil evidence of elytra reduction in ship-timber beetles. Sci. Rep. 9, 4938 (2019).

6. Poinar, G. O. Life in amber (Stanford University Press, Stanford, 1992).

7. Penney, D. \& Green, D. I. Introduction, preparation, study \& conservation of amber inclusions in Biodiversity of fossils in amber from the major world deposits (ed. Penney, D.) 5-21 (Manchester: Siri Scientific Press, 2010).

8. Seyfullah, L. J. et al. Production and preservation of resins - past and present. Biol. Rev. 93, 1684-1714 (2018).

9. Gimmel, M. L., Szawaryn, K., Cai, C. \& Leschen, R. A. B. Mesozoic sooty mould beetles as living relicts in New Zealand. Proc. R. Soc. B 286, 20192176 (2019).

10. Kirejtshuk, A. G. The evolutionary history of the Coleoptera. Geosciences 10, 103 (2020).

11. Alekseev, V. I. Coleoptera from the middle-upper Eocene European ambers: generic composition, zoogeography and climatic implications. Zootaxa 4290, 401-443 (2017).

12. Peris, D. Coleoptera in amber from Cretaceous resiniferous forests. Cretac. Res. 113, 104484 (2020).

13. Peris, D. \& Rust, J. Cretaceous beetles (Insecta: Coleoptera) in amber: the palaeoecology of this most diverse group of insects. Zool. J. Linnean Soc. 189, 1085-1104 (2020).

14. Arriaga-Varela, E. et al. Micro-CT reveals hidden morphology and clarifies the phylogenetic position of Baltic amber water scavenger beetles (Coleoptera: Hydrophilidae). Historical Biology; https://doi.org/10.1080/08912963.2019.1699921 (2019).

15. Peris, D. et al. Unlocking the mystery of the mid-Cretaceous Mysteriomorphidae (Coleoptera: Elateroidea) and modalities in transiting from gymnosperms to angiosperms. Sci. Rep. 10, 16854 (2020).

16. Dierick, M. et al. Micro-CT of fossils preserved in amber. Nucl. Instrum. Methods Phys. Res. A 580, 641-643 (2007).

17. Dunlop, J. A. et al. Computed tomography recovers data from historical amber: an example from huntsman spiders. Naturwissenschaften 98, 519-527 (2011).

18. Peñalver, E. et al. Ticks parasitised feathered dinosaurs as revealed by Cretaceous amber assemblages. Nat. Commun. 8, 1924 (2017).

19. Liu, W., Rühr, P. T. \& Wesener, T. A look with $\mu$ CT technology into a treasure trove of fossils: the first two fossils of the millipede order Siphoniulida discovered in Cretaceous Burmese amber (Myriapoda, Diplopoda). Cret. Res. 74, 100-108 (2017).

20. Keyser, D. \& Friedrich, F. An exceptionally well preserved new species of ostracod (Crustacea) with soft parts in Baltic amber. Hist. Biol. 29, 53-62 (2017).

21. Barták, M. Yantaromyiidae, a new family of Diptera (Brachycera: Schizophora) from Tertiary Baltic amber and X-ray synchrotron microtomography imaging of its structures. J. Syst. Palaeontol. 18, 187-195 (2020).

22. Xing, L. et al. A feathered dinosaur tail with primitive plumage trapped in Mid-Cretaceous amber. Curr. Biol. 26, 3352-3360 (2016).

23. Xing, L. et al. A mid-Cretaceous embryonic-to-neonate snake in amber from Myanmar. Sci. Adv. 4, eaat5042 (2018).

24. Schmidt, J. \& Michalik, P. The ground beetle genus Bembidion Latreille in Baltic amber: Review of preserved specimens and first 3D reconstruction of endophallic structures using X-ray microscopy (Coleoptera, Carabidae, Bembidiini). ZooKeys 662, 101-126 (2017).

25. Bukejs, A., Bezděk, J., Alekseev, V. I., Kairišs, K. \& McKellar, R. C. Description of the male of fossil Calomicrus eocenicus Bukejs et Bezděk (Coleoptera: Chrysomelidae: Galerucinae) from Eocene Baltic amber using X-ray microtomography. Foss. Rec. 23, 105-115 (2020).

26. Bukejs, A. \& Legalov, A. A. The first record of Brentidae (Coleoptera) in Eocene Rovno amber with description of a new fossil species of Toxorhynchus Scudder, 1893. Foss. Rec. 23, 169-177 (2020).

27. Nabozhenko, M. V., Kairišs, K. \& Bukejs, A. The oldest fossil darkling beetle of the genus Neomida Latreille, 1829 (Coleoptera: Tenebrionidae) from Eocene Baltic amber examined with X-ray microtomography. Zootaxa 4768, 435-442 (2020).

28. Larsson, S. G. Baltic amber - a palaeobiological study. Entomonograph 1, 1-192 (1978).

29. Weitschat, W. \& Wichard, W. Baltic Amber in Biodiversity of fossils in amber from the major world deposits (ed. Penney, D.) 80-115 (Manchester: Siri Scientific Press, 2010).

30. Alekseev, V. I. \& Alekseev, P. I. New approaches for reconstruction of the ecosystem of an Eocene amber forest. Biol. Bull. 43, 75-86 (2016).

31. Langenheim, J. H. Plant resins: chemistry, evolution, ecology, and ethnobotany (Timber Press, Portland, 2003).

32. Andrée, K. Der Bernstein. Das Bernsteinland und sein Leben. (Kosmos, Francksche Verhandlung, Stuttgart, 1951).

33. Wolfe, A. P. et al. A new proposal concerning the botanical origin of Baltic amber. Proc. R. Soc. B 276, 3403-3412 (2009).

34. Lambert, J. B., Santiago-Blay, J. A., Wu, Y. \& Levy, A. J. Examination of amber and related materials by NMR spectroscopy. Magn. Reson. Chem. 53, 2-8 (2015).

35. Sadowski, E.-M., Schmidt, A. R., Seyfullah, L. J. \& Kunzmann, L. Conifers of the "Baltic amber forest" and their palaeoecological significance. Stapfia 106, 1-73 (2017).

36. Bogri, A., Solodovnikov, A. \& Żyła, D. Baltic amber impact on historical biogeography and palaeoclimate research: Oriental rove beetle Dysanabatium found in the Eocene of Europe (Coleoptera, Staphylinidae, Paederinae). Pap. Palaeontol. 4, 433-452 (2018).

37. Ritzkowski, S. K-Ar-Altersbestimmungen der bernsteinführenden Sedimente des Samlandes (Paläogen, Bezirk Kaliningrad). Metalla 66, 19-23 (1997). 
38. Perkovsky, E. E., Rasnitsyn, A. P., Vlaskin, A. P. \& Taraschuk, M. V. A comparative analysis of the Baltic and Rovno amber arthropod faunas: representative samples. Afr. Invertebr. 48, 229-245 (2007).

39. Aleksandrova, G. N. \& Zaporozhets, N. I. Palynological characteristic of the Upper Cretaceous and Paleogene sediments of the western part of the Sambian peninsula (the Kaliningrad region), Part 2. Stratigr. Geol. Correl. 16, 528-539 (2008).

40. Bukejs, A., Alekseev, V. I. \& Pollock, D. A. Waidelotinae, a new subfamily of Pyrochroidae (Coleoptera: Tenebrionoidea) from Baltic amber of the Sambian peninsula and the interpretation of Sambian amber stratigraphy, age and location. Zootaxa 4664, 261-273 (2019).

41. Calder, A. A. Click Beetles: Genera of Australian Elateridae (Coleoptera). Monographs on invertebrate taxonomy, Vol. 2. (CSIRO Publishing, Collingwood, 1996).

42. Costa, C., Lawrence, J. F. \& Rosa, S. P. Elateridae Leach, 1815 in Coleoptera, Beetles; Volume 2: Morphology and Systematics (Elateroidea, Bostrichiformia, Cucujiformia partim) (eds. Leschen, R. A. B., Beutel, R. G. \& Lawrence, J. F) in Handbook of Zoology, Arthropoda: Insecta (eds. Kristensen, N. P. \& Beutel, R. G.) 75-103 (Berlin/New York: Walter de Gruyter GmbH \& Co, 2010).

43. Kundrata, R., Gunter, N. L., Janosikova, D. \& Bocak, L. Molecular evidence for the subfamilial status of Tetralobinae (Coleoptera: Elateridae), with comments on parallel evolution of some phenotypic characters. Arthropod. Syst. Phyl. 76, 137-145 (2018).

44. Kusy, D., Motyka, M., Bocek, M., Vogler, A. P. \& Bocak, L. Genome sequences identify three families of Coleoptera as morphologically derived click beetles (Elateridae). Sci. Rep. 8, 17084 (2018).

45. Kundrata, R. \& Bocak, L. Molecular phylogeny reveals the gradual evolutionary transition to soft-bodiedness in click-beetles and identifies Sub-Saharan Africa as a cradle of diversity for Drilini (Coleoptera: Elateridae). Zool. J. Linn. Soc. 187, 413-452 (2019).

46. Bi, W.-X., He, J.-W., Chen, C.-C., Kundrata, R. \& Li, X.-Y. Sinopyrophorinae, a new subfamily of Elateridae (Coleoptera, Elateroidea), with the first record of a luminous click beetle in Asia and evidence for multiple origins of bioluminescence in Elateridae. ZooKeys 864, 79-97 (2019).

47. Kundrata, R., Prosvirov, A. S., Vondracek, D. \& Sormova, E. Congruence between molecular data and morphology: phylogenetic position of Senodoniini (Coleoptera: Elateridae). Insects 10, 231 (2019).

48. Kirejtshuk, A. G. \& Ponomarenko, A. G. Taxonomical list of fossil beetles of the suborder Scarabaeina (part 2). Available at https ://www.zin.ru/Animalia/Coleoptera/eng/paleosyl.htm (2015).

49. Sohn, J. C., Nam, G. S., Choi, S. W. \& Ren, D. New fossils of Elateridae (Insecta, Coleoptera) from Early Cretaceous Jinju Formation (South Korea) with their implications to evolutionary diversity of extinct Protagrypninae. PLoS ONE 14, e0225502 (2019).

50. Ponomarenko, A. G. The geological history of beetles in Biology, phylogeny and classification of Coleoptera: papers celebrating the 80th birthday of Roy A. Crowson (eds. Pakaluk, J. \& Ślipiński, S. A.) 87-155 (Warszawa: Muzeum i Instytut Zoologii PAN, 1995).

51. Kundrata, R., Packova, G. \& Hoffmannova, J. Fossil genera in Elateridae (Insecta, Coleoptera): a Triassic origin and Jurassic diversification. Insects 11, 394 (2020).

52. Hieke, F. \& Pietrzeniuk, E. Die Bernstein-Käfer des Museums zur Naturkunde, Berlin (Insecta, Coleoptera). Mitt. Mus. Nat.kd. Berl. 60, 297-326 (1984).

53. Iablokoff-Khnzorian, S. M. Novye zhestkokrylye semeystva Elateridae iz baltiyskogo yantayra. Paleontol. Zh. 1961, 84-97 (1961).

54. Alekseev, V. I. The beetles (Insecta: Coleoptera) of Baltic amber: the checklist of described species and preliminary analysis of biodiversity. Zool. Ecol. 23, 5-12 (2013).

55. Helm, O. Beiträge zur Kenntiss der Insecten des Bernsteins. Schrift. Nat. Ges. Danzig 9, 220-231 (1896).

56. Handlirsch, A. Die Fossilen Insekten und die Phylogenie der Rezenten Formen, part V. Ein Handbuch fur Palaontologen und Zoologen. 641-800 (Leipzig: Wilhelm Engelmann, 1907).

57. Klebs, R. Über Bernsteineinschlüsse in allgemeinen und die Coleopteren meiner Bernsteinsammlung. Schr. Physik.-ökonom. Ges. Königsberg 51, 217-242 (1910).

58. Bachofen-Echt, A. D. Bernstein und seine Einschlüsse (Springer, Wien, 1949).

59. Spahr, U. Systematischer Katalog der Bernstein- und Kopal-Käfer (Coleoptera). Stuttg. Beitr. Naturkd. Ser. B. 80, 1-107 (1981).

60. Arias-Bohart, E. T. Tunon, a new genus of Protelaterini (Elateridae: Lissominae) from southern Chile. Pan.-Pac. Entomol. 89, 159-167 (2013).

61. Lawrence, J. F. \& Arias, E. T. Valdivelater, a new genus of Protelaterini (Elateridae: Lissominae) from the forests of central and southern Chile. Ann. Zool. 59, 319-328 (2009).

62. Alekseev, V. I. A new coleopterous family Wabbelidae fam. nov. (Coleoptera: Cucujoidea) from Baltic amber (Cenozoic, Paleogene, Eocene). Baltic J. Coleopterol. 17, 29-41 (2017).

63. Winkler, J. R. Berendtimiridae fam. n., a new family of fossil beetles from Baltic Amber. Mitt. Münch. Entomol. Ges. 77, 51-59 (1987).

64. Nabozhenko, M. V. The fossil record of darkling beetles (Insecta: Coleoptera: Tenebrionidae). Geosciences 9, 514 (2019).

65. Brunke, A. J., Żyła, D., Yamamoto, S. \& Solodovnikov, A. Baltic amber Staphylinini (Coleoptera: Staphylinidae: Staphylininae): a rove beetle fauna on the eve of our modern climate. Zool. J. Linn. Soc. 187, 166-197 (2019).

66. Kusy, D. et al. Genome sequencing of Rhinorhipus Lawrence exposes an early branch of the Coleoptera. Front. Zool. 15, 21 (2018).

67. McKenna, D. D. et al. The evolution and genomic basis of beetle diversity. Proc. Natl. Acad. Sci. U. S. A. 116, 24729-24737 (2019).

68. Zhang, S. Q. et al. Evolutionary history of Coleoptera revealed by extensive sampling of genes and species. Nat. Comm. 9, 205 (2018).

69. Peris, D., Ruzzier, E., Perrichot, V. \& Delclòs, X. Evolutionary and paleobiological implications of Coleoptera (Insecta) from Tethyan-influenced Cretaceous ambers. Geosci. Front. 7, 695-706 (2016).

70. Douglas, H. Phylogenetic relationships of Elateridae inferred from adult morphology, with special reference to the position of Cardiophorinae. Zootaxa 2900, 1-45 (2011).

71. Arias-Bohart, E. T. Malalcahuello ocaresi gen. \& sp. n. (Elateridae, Campyloxeninae). ZooKeys 508, 1-13 (2015).

72. Calder, A. A., Lawrence, J. F. \& Trueman, J. W. H. Austrelater, gen. nov. (Coleoptera: Elateridae), with a description of the larva and comments on elaterid relationships. Invertebr. Taxon. 7, 1349-1394 (1993).

73. Kolibáč, J., Schmied, H., Wappler, T. \& Kubisz, D. A description of Promanodes serafini gen. et sp. nov. from Baltic amber, with a review of related New Zealand Promanus Sharp, 1877 (Coleoptera: Trogossitidae). Zootaxa 2620, 29-44 (2010).

74. Klass, K. D., Zompro, O., Kristensen, N. P. \& Adis, J. Mantophasmatodea: a new insect order with extant members in the Afrotropics. Science 296, 1456-1459 (2002).

75. Kovalev, A. V. \& Kirejtshuk, A. G. Asiopsectra gen. n., a second genus of the family Brachypsectridae (Coleoptera, Elateroidea) from the Palaearctic Region. Insect Syst. Evol. 47, 195-208 (2016).

76. Schimmel, R., Platia, G. \& Tarnawski, D. A new genus Sinoaplastinus, with a new species S. kadeji from China, the first elateridbeetle with bi-lamellate antennomeres from the Palaearctic Region (Insecta: Coleoptera: Elateridae). Genus 19, 669-674 (2008).

77. Otto, R. L. Descriptions of two new elateroid beetles (Coleoptera: Eucnemidae, Elateridae) from Burmese amber. Insecta Mundi 702, 1-6 (2019).

\section{Acknowledgements}

The authors are sincerely grateful to Elżbieta Sontag (Museum of Amber Inclusions, University of Gdańsk, Poland) for the loan of the examined specimen, to Kristaps Kairišs (Daugavpils University, Daugavpils, Latvia) for the assistance in X-ray micro-computed tomography, and to Jonas Damzen (Vilnius, Lithuania) for the assistance 
during our amber research and permission to use photographs of the holotype. Additionally, we would like to express our sincere gratitude to David Peris (Germany) and Karol Szawaryn (Poland) for providing some literature, to Václav Dušánek (Czech Republic) and Christel and Hans Werner Hoffeins (Germany) for the photographs of fossil Elateridae in their collections, to Evgeny V. Yan (PIN, Russia) for the photographs of some Elateridae types from the PIN, Russia, to Václav Dušánek, Michael A. Ivie (USA), Elizabeth T. Arias-Bohart (USA), John F. Lawrence (Australia), and Hume Douglas (Canada) for the discussions on the placement of the examined fossil specimen, to David Peris and Martin Fikáček (Czech Republic) for their valuable suggestions leading to the improvement of the manuscript, and to Matthew L. Gimmel (USA) for proofreading the manuscript. This research was funded by the internal grant of the Palacky University nr. IGA_PrF_2020_026 (RK, JH), the Moscow State University grant for leading scientific schools "Depository of the living systems" in frame of the MSU development program, and the Moscow State University research project No. AAAA-A16-116021660095-7 (both AP).

\section{Author contributions}

R.K. and A.B. conceived and designed the study. A.B. conducted the micro-CT scanning. R.K., A.S.P. and J.H. carried out the morphological investigation. R.K. wrote the initial manuscript with help of A.B. and A.S.P. All authors performed the literature search, discussed the results, and edited, reviewed and approved the manuscript.

\section{Competing interests}

The authors declare no competing interests.

\section{Additional information}

Supplementary information is available for this paper at https://doi.org/10.1038/s41598-020-76908-3.

Correspondence and requests for materials should be addressed to R.K.

Reprints and permissions information is available at www.nature.com/reprints.

Publisher's note Springer Nature remains neutral with regard to jurisdictional claims in published maps and institutional affiliations.

(c) (i) Open Access This article is licensed under a Creative Commons Attribution 4.0 International cc) License, which permits use, sharing, adaptation, distribution and reproduction in any medium or format, as long as you give appropriate credit to the original author(s) and the source, provide a link to the Creative Commons licence, and indicate if changes were made. The images or other third party material in this article are included in the article's Creative Commons licence, unless indicated otherwise in a credit line to the material. If material is not included in the article's Creative Commons licence and your intended use is not permitted by statutory regulation or exceeds the permitted use, you will need to obtain permission directly from the copyright holder. To view a copy of this licence, visit http://creativecommons.org/licenses/by/4.0/.

(C) The Author(s) 2020 